\title{
A Facile Strategy for Preparing Superhydrophobic Coating on AZ31 Magnesium Alloy with Stable Anticorrosion Performance
}

\author{
Shidong Wang ${ }^{1,2}$, Huifang Zhang ${ }^{1,2}$, Zhiqiang Qian ${ }^{1,2}$, Xiushen $Y e^{1,2, *}$, Zhijian $W u^{1,2, *}$, Shengting $\mathrm{Li}^{3}$ \\ ${ }^{1}$ Key Laboratory of Comprehensive and Highly Efficient Utilization of Salt Lake Resources, Qinghai \\ Institute of Salt Lakes, Chinese Academy of Sciences, Xining 810008, China \\ ${ }^{2}$ Key Laboratory of Salt Lake Resources Chemistry of Qinghai Province, Xining 810008, China \\ ${ }^{3}$ Qinghai Salt Lake Industry Co., Ltd., Golmud 816099, China \\ *E-mail: yexs@isl.ac.cn, zjwu@isl.ac.cn
}

doi: $10.20964 / 2020.09 .44$

Received: 13 May 2020 / Accepted: 3 July 2020 / Published: 10 August 2020

Superhydrophobic coating on magnesium alloy by employing polydopamine@ $\mathrm{SiO}_{2}\left(\mathrm{PDA} @ \mathrm{SiO}_{2}\right)$ particles and silane via a facile one-step spraying technique was prepared in this study. Surface morphology, chemical compositions, roughness and wettability of the coating were comprehensively investigated by Field Emission Scanning Electron Microscopy (FESEM), Fourier Transform Infrared Spectra (FTIR), 3D optical microscope and contact angle techniques, respectively. Corrosion resistance of the coating was evaluated by electrochemical impedance spectroscopy (EIS). Results indicated that the coating exhibited superhydrophobicity due to its micropapillae structure and low surface energy of silica aggregates. The coating showed outstanding superhydrophobicity with contact angle (CA) larger than $154^{\circ}$ and sliding angle (SA) less than $3^{\circ} .|\mathrm{Z}|_{0.01 \mathrm{~Hz}}$ of superhydrophobic coated sample reached 6.916 $\times 10^{8} \Omega \cdot \mathrm{cm}^{2}$, which showed excellent corrosion performance. The superhydrophobic coating can protect the specimen surface from being eroded even after fifteen days immersion in $\mathrm{NaCl}$ solution, indicating that the coating had a strong stability in corrosive media.

Keywords: PDA@ $\mathrm{SiO}_{2}$, Superhydrophobic, Magnesium alloy, Anticorrosion

\section{$\underline{\text { FULL TEXT }}$}

(C) 2020 The Authors. Published by ESG (www.electrochemsci.org). This article is an open access article distributed under the terms and conditions of the Creative Commons Attribution license (http://creativecommons.org/licenses/by/4.0/). 